\title{
FAULT SLIP IN SOUTHERN CALIFORNIA
}

\author{
By John N. Louie, Clarence R. Allen, David C. Johnson, Paul C. Haase, \\ AND STEPHEN N. CoHN
}

\begin{abstract}
Measurements of slip on major faults in southern California have been performed over the past $18 \mathrm{yr}$ using principally theodolite alignment arrays and tautwire extensometers. They provide geodetic control within a few hundred meters of the fault traces, which complements measurements made by other techniques at larger distances. Approximately constant slip rates of from 0.5 to $5 \mathrm{~mm} / \mathrm{yr}$ over periods of several years have been found for the southwestern portion of the Garlock fault, the Banning and San Andreas faults in the Coachella Valley, the Coyote Creek fault, the Superstition Hills fault, and an unnamed fault $20 \mathrm{~km}$ west of El Centro. These slip rates are typically an order of magnitude below displacement rates that have been geodetically measured between points at greater distances from the fault traces. Exponentially decaying postseismic slip in the horizontal and vertical directions due to the 1979 Imperial Valley earthquake has been measured. It is similar in magnitude to the coseismic displacements. Analysis of seismic activity adjacent to slipping faults has shown that accumulated seismic moment is insufficient to explain either the constant or the decaying postseismic slip. Thus the mechanism of motion may differ from that of slipping faults in central California, which move at rates close to the plate motion and are accompanied by sufficient seismic moment. Seismic activity removed from the slipping faults in southern California may be driving their relatively aseismic motion.
\end{abstract}

\section{INTRODUCTION}

Since 1967, the Seismological Laboratory at the California Institute of Technology has monitored slip on the traces of major faults in Southern California (Figures 1 and 2) with theodolite alignment arrays, taut-wire creepmeters, and nail arrays at more than 30 locations. Alignment array measurements of displacements on three different faults triggered by the 1968 Borrego Mountain earthquake were first reported by Allen et al. in 1972. Subsequent observations by creepmeters and alignment arrays in the Imperial Valley to late 1977 were summarized by Goulty $e t$ al. (1978), and by Keller et al. (1978) for alignment arrays throughout southern California. Their work demonstrated the occurrence of slip on portions of the Garlock, San Andreas, San Jacinto, and Imperial fault systems, as well as its absence on other segments. The average rates of fault slip in southern California were shown to be substantially less than slip rates on the San Andreas system in central California. Observations of fault slip not directly associated with substantial earthquakes have been made outside of California on just one other fault segment, in Turkey (Aytun, 1980).

The surface faulting associated with the 1979 Imperial Valley earthquake ruptured across 4 creepmeters, 2 nail arrays, and 3 alignment arrays straddling the Imperial fault and the Brawley fault zone. Cohn et al. (1982) have summarized the measurements of this event by creepmeters and nail arrays, including the lack of premonitory creep and the first record ever obtained indicating the actual velocity of the surface displacement. 
The purpose of this paper is to present recently acquired observations and to integrate them with previously published slip data and seismicity information into a more comprehensive picture of fault behavior in southern California.

A note on the terminology used herein is in order. Any tectonic shear dislocation localized to a fault and parallel to it is termed "slip." "Creep" implies more-or-less continuous slip. A "displacement" refers to a discrete episode of unusually rapid

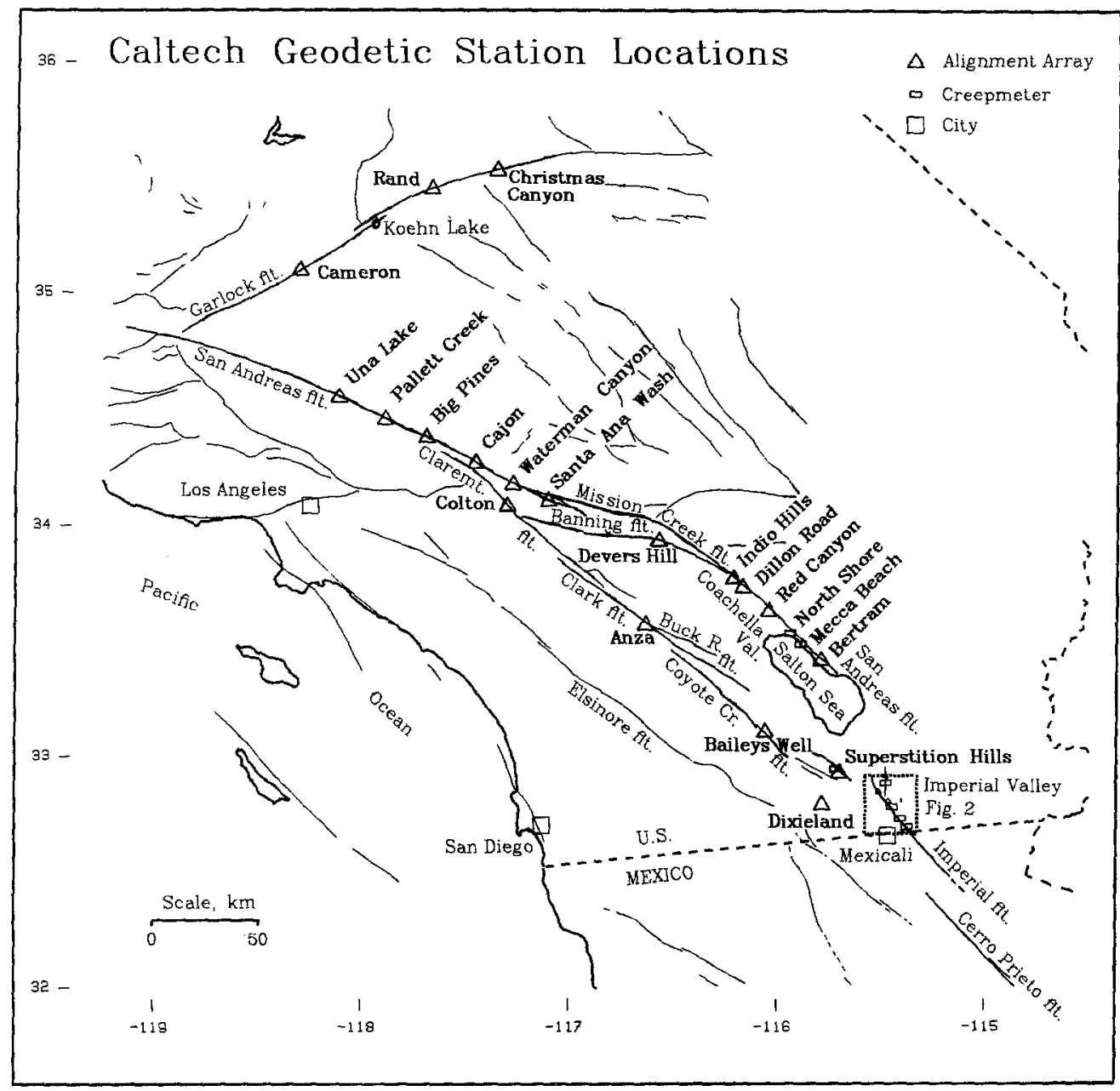

FIG. 1. Map showing Caltech theodolite alignment array and creepmeter locations across major faults in southern California. Stations in the Imperial Valley, the area inside the dotted box, are shown in Figure 2.

slip taking place over a very limited period of time, such as during a seismic event or as a "creep event." "On-going" or "continuing" slip describes a process of continuous creep and/or repeated episodic displacements which produce an approximately constant rate of slip when averaged over the period between measurements. "Seismic slip" is the term used to describe creep or displacements occurring during or after an earthquake having recognized surface rupture, at time-varying rates. "Nonseismic" refers to slip that is not directly related to such events. 


\section{METHODS}

Three types of instrumentation were used in this study to determine fault slip: theodolite alignment arrays, taut-wire creepmeters, and nail arrays. All measure surface deformation across and very close to a fault trace, between one and a few hundred meters away. Figures 1 and 2 show the locations of these geodetic stations within southern California.

Alignment arrays. Twenty-four theodolite alignment arrays across nine major faults in southern California were established by Caltech starting in 1967. They are

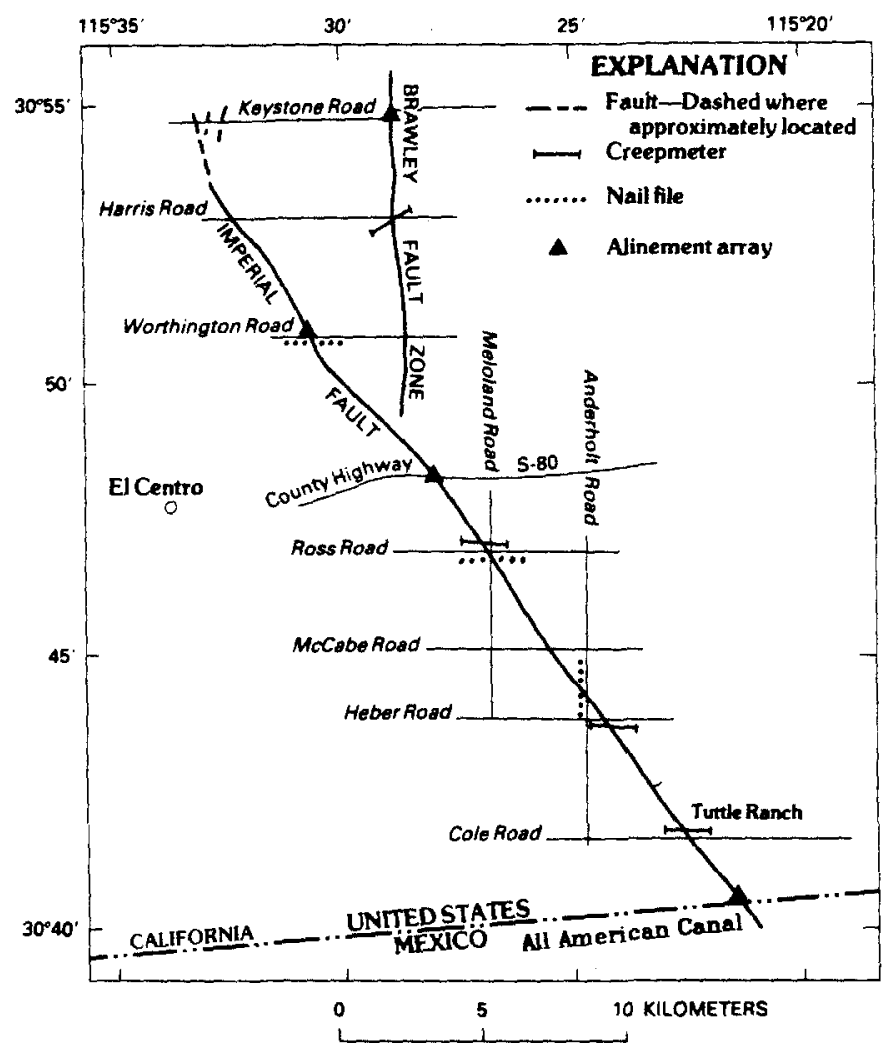

FIG. 2. Locations of Caltech creepmeters, alignment arrays, and nail-file arrays on the Imperial fault and the Brawley fault zone in the Imperial Valley (from Cohn et al., 1982).

resurveyed on an annual, semi-annual, or quarterly basis. These arrays are smallscale triangulation networks comprising between 6 and 10 survey targets straddling the fault trace and distributed over a few hundred meters. Figure 3 shows the components of an alignment array: a theodolite station, reference targets, and measurement targets. The theodolite station is set up within a few tens of meters of the fault trace. It is simply a $70-\mathrm{cm}$-long steel stake driven into the ground, the top of which is marked to allow centering of the theodolite with an optical plummet. The survey targets are scribed metal markers permanently attached to additional steel stakes or other fixed objects. Reference targets are placed on the same side of the fault as the theodolite station, and are distributed both along a line parallel to the fault, and behind the theodolite to test for motion distributed away from the 
fault trace. Measurement targets are installed on the side of the fault opposite the theodolite station. A Wild T-2 1-sec theodolite is used to survey the angles between the targets. Six horizontal and two vertical angle readings are made of each target for each resurvey. These measurements yield the angles between pairs of targets. Each pair consists of a reference target and a measurement target; and each reference target is paired with each measurement target. This redundancy allows for cross-comparisons to check the accuracy of the sightings to each target and their fixity. Thus, for example, an alignment array consisting of 4 reference targets and 5 measurement targets will yield, for each reference target, 5 angles between the reference and the 5 measurement targets, for a total of 20 angles for all 4

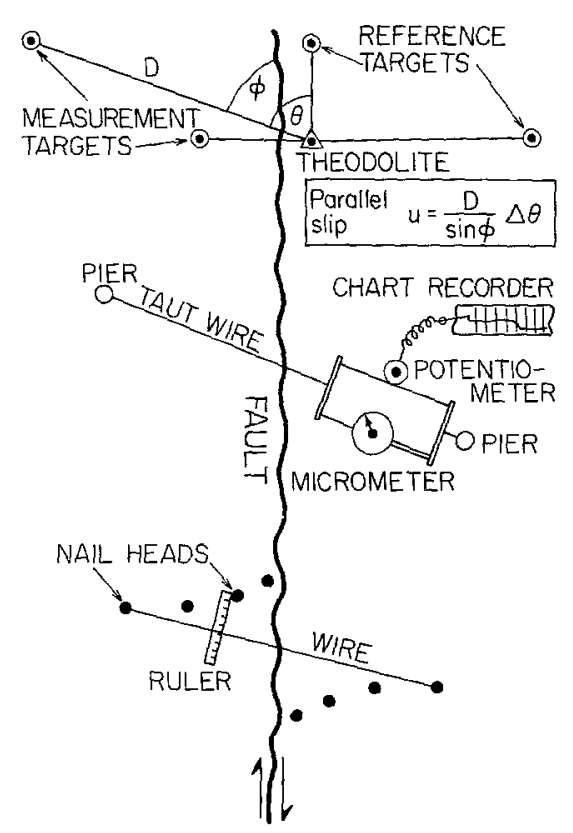

FIG. 3. Schematic representation of, from top to bottom, a theodolite alignment array, a creepmeter, and a nail array of the types used in this study.

reference targets. Each of the 20 angles corresponds to the angle between a different pair of reference and measurement targets.

The change in the angle between a paired reference and measurement target between two resurveys can be converted into a displacement between the measurement target and the theodolite station under the assumption that all motion is parallel to the fault trace, where

$$
u=\frac{D}{\sin \varphi} \Delta \theta
$$

and $u$ is the amount of parallel slip, $D$ is the distance from the theodolite to the measurement target, $\varphi$ is the angle between the fault trace and a line from the theodolite to the measurement target, and $\Delta \theta$ is the change in the angle between the measurement target and a reference target (Figure 3). Thus, only the target 
angles need to be measured with great accuracy. The fault angle and target distances are determined to within a few per cent.

Figure $4 \mathrm{~A}$ shows the data derived from resurveys of an experimental alignment array set up at the Seismological Laboratory in Pasadena, presumably a location free of contemporary tectonic movement. The triangle represents the initial survey. Three subsequent surveys are shown in the figure. The array consists of 3 reference and 3 measurement targets, yielding a total of 9 angles and therefore 9 slip
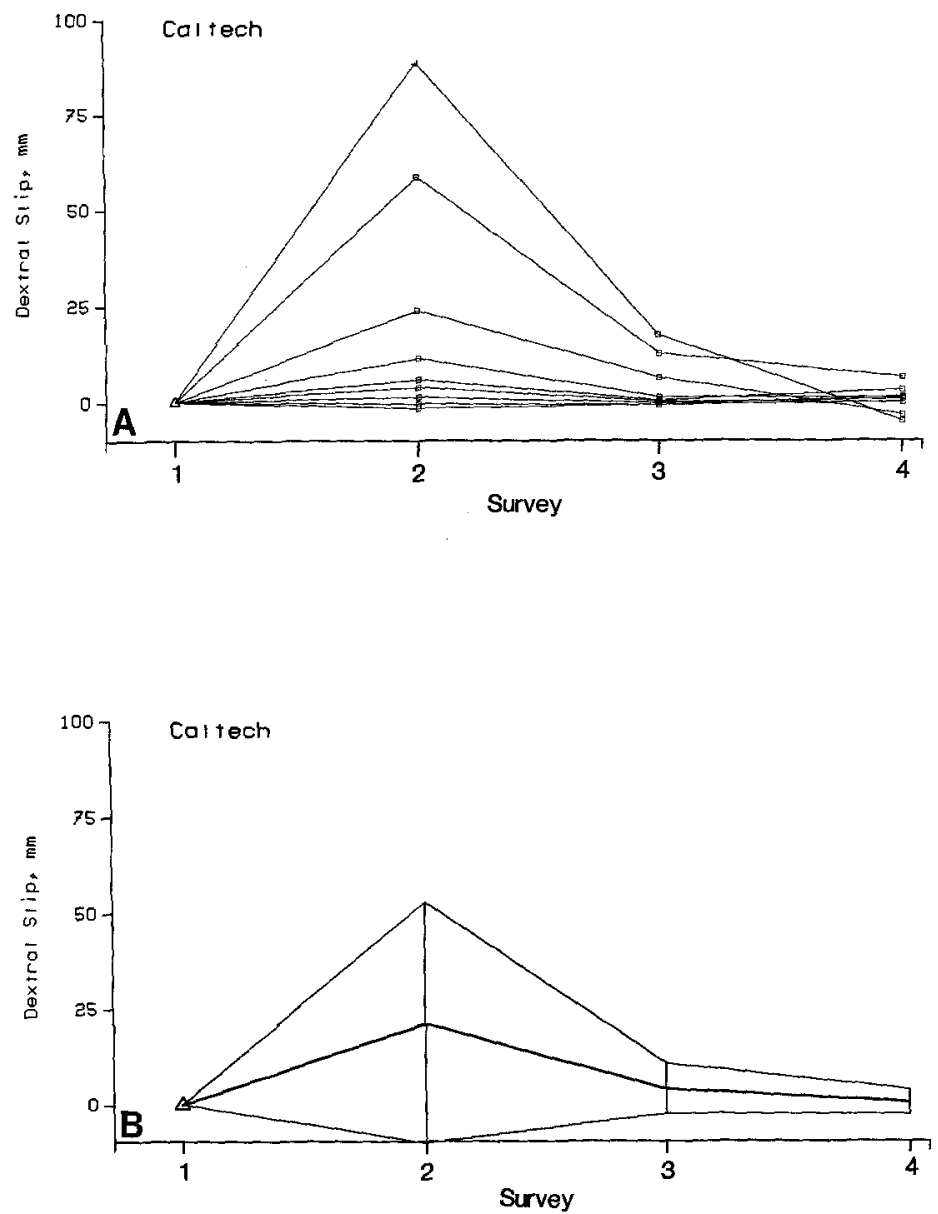

FIG. 4. (A) Record of measurements of an experimental alignment array set up at Caltech. All of the surveys were performed within a period of several weeks; the ordinate indicates the sequence of the surveys. See text for details. (B) The same record of measurements of the experimental array now averaged under the rigid-block assumption. The three lines represent the average of measurements between different target pairs, and the average plus and minus one standard deviation. A vertical line is plotted at each resurvey.

measurements $u$ for each of the surveys. Each slip value $u$ is plotted as a small box. The lines connect slip values from a particular target pair between two surveys. Thus, the slip plotted for each target pair represents the offset of the measurement target of that pair, parallel to the fault trace, from its position at the initial survey.

Errors can be introduced into the data from several sources, including: (1) errors in the initial survey, which is generally used to determine the slips at all subsequent 
surveys; (2) measurement errors, such as inaccuracies in centering the theodolite on the instrument station or in pointing the theodolite telescope at the survey targets; and (3) disturbances of the targets not related to tectonic motion, for example, soil settling or human interference. Some of these errors are seen in Figure $4 \mathrm{~A}$ for the experimental array and are representative of the errors encountered in the data from many of the alignment arrays. The initial survey of an array is usually done immediately following the installation of the theodolite station and targets. These are prone to settlement in the days following their installation, after which most of them stabilize. Since subsequent resurveys are usually compared to the initial survey, the slip data will show a constant offset for each resurvey. Some evidence for a few millimeters of static offset can be seen in the lower five lines of Figure 4A. If a single resurvey shows large angle changes in most of the target pairs, one can suspect poor centering of the theodolite. This could explain the large deviations of the second survey. Nontectonic motion of a reference target, or a poor sighting to it, produces a similar pattern: the angle to a reference target is subtracted from the angle to each measurement target, causing a constant $\Delta \theta$ between each pair. By equation (1), this will produce apparent slips for measurement targets paired with the disturbed reference target, which increase in proportion to the distance of the measurement target. This type of pattern is easily recognized and has allowed inaccurate sightings of reference targets to be culled from the data.

In addition, we have assumed that all motion is localized to the fault trace itself, so that the areas on either side of the trace behave as rigid blocks. A good case for motion away from the fault trace can be made for only one of our alignment arrays in southern California, at Cameron on the Garlock fault (Figure 1). Elsewhere, possibly due to incomplete target coverage around the faults, the assumption of rigid blocks holds to within the surveying accuracy. Homogeneous shearing such as that observed by Burford and Harsh (1980) on the San Andreas fault in central California would not be detectable with the Caltech arrays. Using the rigid-block assumption, the slips for different target pairs may be averaged and plotted as in Figure $4 \mathrm{~B}$, which shows the average (heavy line) and standard deviation of the slips calculated for each resurvey. Measurement targets undergoing nontectonic movement can usually be distinguished and culled from the average, yielding an accuracy of 1 to $5 \mathrm{~mm}$ for many arrays. Since the standard deviations from the averages of all the target pairs are usually comparable to or larger than those for one pair, the standard deviation of all pairs will be regarded as the "error" of the resurvey under the rigid-block assumption.

After many resurveys, it is usually clear how sensitive a particular alignment array is to different types of motions. Large statistical errors for many resurveys can make an array insensitive to continuing slip below a certain rate, and a history of large variations between consecutive surveys can yield insensitivity to episodic displacements of less than a certain magnitude. The approximate sensitivities found for selected alignment arrays are given in Table 1. The arrays in Table 1 are those which, when averaged over their measurement lifetime, have not shown any significant offset, as discussed below in the observations section. The sensitivity to continuing slip is the highest slip rate that could have occurred over the life of the array that still fits within two times the standard deviation of some of the first and the most recent resurveys. It is larger for the arrays that show larger errors for individual resurveys. The sensitivity to episodic displacements is the largest difference in slip measured on the array between two consecutive resurveys. In some cases the two resurveys were made within hours of each other. In the discussion of 
the observations at these arrays, below, any apparent motions less than the sensitivities given in Table 1 will not be regarded as significant. While these sensitivities apply to the arrays crossing stable fault traces, they may not be representative of the sensitivities of arrays crossing fault traces in motion.

Since only two readings are made of the vertical angle to each target, and vertical sightings are much more subject to atmospheric refraction effects, reliable vertical motions are not generally resolved. Tectonic events producing large displacements have, however, yielded useful records of vertical displacements. Here, also, only motion parallel to the vertical direction can be resolved, and the rigid-block assumption allows the average and standard deviation of the relative displacement to be calculated.

The alignment arrays represent our most widespread measurement technique, monitoring motions within a few hundred meters of a fault trace and parallel to it.

TABLE 1

\begin{tabular}{lcc}
\multicolumn{1}{c}{ Afray } & $\begin{array}{c}\text { Continuing Slip } \\
\text { (mm/yr) }\end{array}$ & $\begin{array}{c}\text { Episodic } \\
\text { Displacements } \\
\text { (cm) }\end{array}$ \\
\hline All American Canal & 5 & 1 \\
Colton & 1 & 1 \\
Anza, 139 m aperture & 1 & 1 \\
Anza, 270 m aperture & 2 & 3 \\
Una Lake & 0.5 & 1 \\
Pallett Creek & 0.2 & 1 \\
Big Pines & 1 & 0.5 \\
Waterman Canyon & 1 & 2 \\
Santa Ana Wash & 0.4 & 1 \\
Rand & 0.1 & 0.1 \\
Christmas Canyon & 0.5 & 0.3 \\
\hline
\end{tabular}

They are valuable for characterizing the slip on a fault over periods of years with an accuracy of a millimeter per year.

Creepmeters. Seven taut-wire creepmeters (extensometers) are maintained by Caltech across some of the more active faults in southern California (Figures 1 and 2). Four record continuously on strip-chart recorders; the one at Mecca Beach is telemetered daily to the Laboratory. These instruments (Figure 3) were described by Cohn et al. in 1982 and are similar to those described by Smith and Wyss (1968) and Yamashita and Burford (1973). It is worth noting, however, that problems with chart recorder speed have allowed creep events to be located in time only to the nearest week. Fortunately, this period is smaller than the usual period between events, allowing tentative correlations of events to be made between different stations. Further, discrepancies have been found between the amount of creep measured by the micrometers and that recorded on the strip-charts. The records suggest that the chart recorders may be insensitive to continuous creep at rates less than $10 \mathrm{~mm} / \mathrm{yr}$. In cases where alignment or nail arrays are near a creepmeter, they have agreed with the micrometer. The strip-charts record every 2 sec and are thus valuable for characterizing the nature of creep events at very short time periods. The lower limit of resolution for episodic displacements is about $0.1 \mathrm{~mm}$, which can only, of course, be resolved into the parallel slip within $10 \mathrm{~m}$ of the fault trace. 
Nail arrays. Three nail arrays (Figure 3) are maintained in the Imperial Valley near other instrumentation (Figure 2). Their measurement has been described by Cohn et al. (1982). Two of these arrays have been placed near creepmeters to provide backup measurements during breakdowns of the creep instruments. Nail arrays are the simplest and most direct type of instrumentation, allowing measurement to \pm 1 $\mathrm{mm}$ of motions between 1 and $15 \mathrm{~m}$ away from the fault over periods of months to years. They serve also to define the width of the shear zone and make it possible to test for nonhomogeneity of the motion.

\section{OBSERVATIONS}

Imperial Valley area. The Imperial Valley has been of central interest since unusual displacement events on the Imperial fault prompted the initial establishment of alignment arrays in the area (Brune and Allen, 1967; Allen et al., 1972). Seven alignment arrays and 5 creepmeters covering the Imperial, Brawley, and Superstition Hills faults have been monitored since 1967, with an additional array $20 \mathrm{~km}$ west of El Centro (Figures 1 and 2). Goulty et al. (1978) provide slip measurements from alignment arrays in the region up to September 1977.

The targets of the alignment array at the All American Canal (Figure 2) have consisted solely of nails driven into small telephone poles. The angle data show no indication of any movement greater than the $1 \mathrm{~cm}$ apparent sensitivity of the array from May 1967, when it was established, to August 1979. The array was surveyed the day after the 15 October 1979 Imperial Valley earthquake. The target displacements found by the resurvey appear at first to indicate fault motion. However, since soil slumping but no tectonic rupture was observed in this area following the 1979 event (Youd and Wieczorek, 1982; Sharp et al., 1982), groundshaking during the earthquake must have caused slumping which displaced the targets. In addition, the pattern of displacements within the geometry of the array indicates that the trace of the Imperial fault revealed by trenching (Sharp, 1977) could not have been offset. From 1979 to the latest measurement in March 1984 no significant motion has been seen. No significant episodic displacements other than those due to groundshaking in 1979 are apparent over the 16-yr life of the array. Thus, a plot of target displacements for this array would be misleading, so one is not shown.

More confidence can be placed in measurements made to the north along the Imperial fault. At Tuttle Ranch (Figure 2), the creepmeter has shown a total of $6 \pm$ $1 \mathrm{~mm}$ of dextral slip since March 1980, essentially accumulated by May 1982 with no further resolvable movement up to the July 1984 service trip. The history of fault slip as recorded by the dial gauge micrometer is plotted in Figure 5B. The additional slip since the 1979 earthquake confirms the total of $10 \mathrm{~mm}$ of coseismic and postseismic displacement due to the event projected by Cohn et al. (1982). The postseismic slip is a factor of 1.5 larger than the coseismic slip. However, it accumulated in only $2.5 \mathrm{yr}$, as opposed to the expected $6 \mathrm{yr}$. The recent 2 -yr quiescent period of less than $0.2 \mathrm{~mm} / \mathrm{yr}$ of slip contrasts with the approximate rate of $1 \mathrm{~mm} / \mathrm{yr}$ found prior to the earthquake by Goulty et al. (1978).

The Heber Road creepmeter is apparently still showing afterslip from the 1979 event (Figure 5A). While the greatest part of the exponentially decaying postseismic slip occurred within a few months of the event, more than a dozen displacement events larger than $2 \mathrm{~mm}$ have been recorded on the strip chart from March 1980 up to the July 1984 reading, which total more than $45 \mathrm{~mm}$. The events continue to occur at larger intervals rather than decrease in size. The micrometer measured a 
total of $86 \mathrm{~mm}$ of creep over the same period, suggesting that $40 \mathrm{~mm}$ of creep occurred at too slow a rate to be recorded on the strip chart. The coseismic slip exceeded the dynamic range of the creepmeter but totaled $55 \mathrm{~cm}$ on the nearby Anderholt Road nail array.

The records from the Ross Road creepmeter (Figure 5A) are similar to those from Heber Road. About $90 \mathrm{~mm}$ of dextral slip had been measured by the micrometer
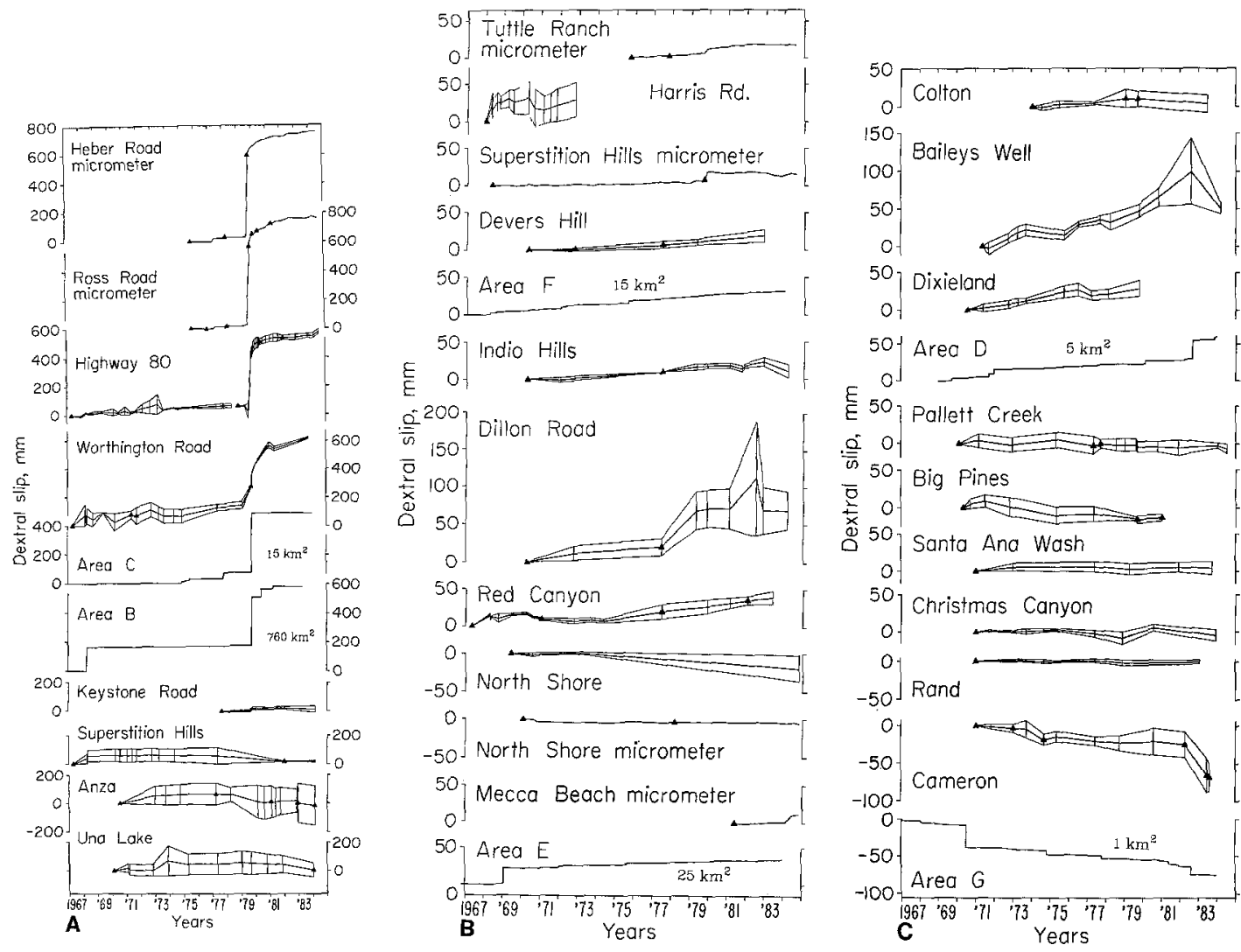

FIG. $\overline{5}$. Records of cumulative horizontal slip from resurveys of 21 alignment arrays and quarterly readings of six creepmeter micrometers, from 1967 through 1984. Station locations are given in Figures 1 and 2. The alignment array records are plotted as in Figure $4 \mathrm{~B}$, with triangles at the initial survey and where values were assumed for new targets based on measurements of previously installed targets. The creepmeter micrometer records represent the values read directly from the instruments on a quarterly basis, corrected for the change in wire length with temperature and for the orientation of the instrument with respect to the fault. Triangles are placed at the initial reading and where the slip had to be recovered from a nearby nail array, some other geodetic measurement, or assumed from previous trends, due to instrument breakdown. The records labeled with "area" show the history of seismically derived slip for the indicated area of Figure 8. The cumulative seismic moment calculated from the local magnitudes, through equation (2), of earthquakes detected within the area by the Southern California Array for Research on Local Earthquakes and Teleseisms (SCARLET) is divided by a rigidity of $3.3 \times 10^{11}$ dynes/ $\mathrm{cm}^{2}$ and the indicated rupture area to yield the seismically derived slip [see equation (3)]. Note that (B) and $(C)$ are plotted at 4 times the vertical scale of $(A)$

from May 1980 to July 1984 . When added to trilateration measurements indicating the amount of coseismic displacement at Ross Road (Crook et al., 1982), the total slip associated with the 1979 earthquake has exceeded $72 \mathrm{~cm}$. The data give no indication that slip has declined to the preevent rate of less than $10 \mathrm{~mm} / \mathrm{yr}$.

At Highway 80, Goulty et al. (1978) and subsequent measurements prior to 
October 1979 show that on-going dextral slip at a rate of about $5 \mathrm{~mm} / \mathrm{yr}$ was taking place prior to the Imperial Valley earthquake. A rate of $2.5 \mathrm{~mm} / \mathrm{yr}$ appears to be normal for the periods between the three episodic displacements recorded in 1968, 1971, and 1973 or 1974, all of which exceeded $1 \mathrm{~cm}$ in magnitude (Figure 5A). The array showed $23 \pm 1 \mathrm{~cm}$ of right-lateral slip within a day of the $1979 \mathrm{event}$, and 29 $\pm 2 \mathrm{~cm}$ of exponentially decaying postseismic creep to the July 1984 measurement. The eastern side of the fault subsided $5.8 \pm 0.2 \mathrm{~cm}$ within a day of the event, with no recognizable dip slip having occurred since then. The horizontal afterslip may be continuing at almost $20 \mathrm{~mm} / \mathrm{yr}$, including any possible episodic displacements. With the high rate of on-going slip, it is difficult to determine what proportions of episodic displacements and continuous creep may be occurring at the array. The present rate is at least twice the rate of continuing slip before the 1979 event.

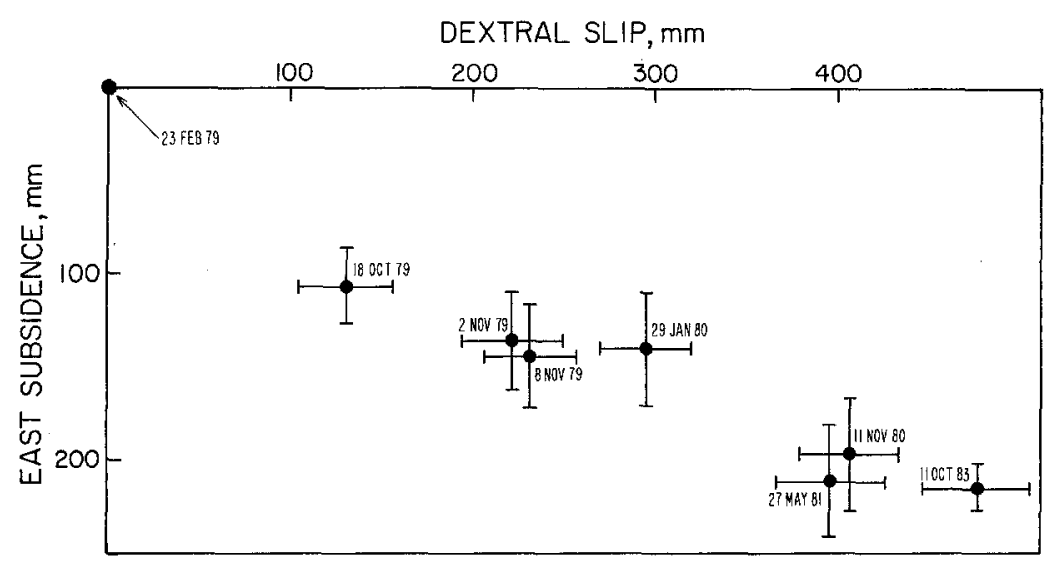

Fig. 6. Projection onto the vertical plane of the coseismic and postseismic displacement vector relative to time at the Worthington Road alignment array (Figure 2), following the 1979 Imperial Valley earthquake. The error bars represent twice the standard deviation of averages over many target pairs under the rigid-block assumption. The displacement becomes more horizontal as postseismic slip progresses.

Farther north, at Worthington Road, on-going dextral slip at $13 \pm 8 \mathrm{~mm} / \mathrm{yr}$ between December 1974 and February 1979 was followed by $15 \pm 1 \mathrm{~cm}$ of displacement within 3 days of the 1979 event. Exponentially decaying postseismic slip has continued to October 1983 for an additional 33 to $36 \mathrm{~cm}$ of right-lateral movement (Figure 5A). Subsidence of $11 \pm 2 \mathrm{~cm}$ was observed to the east of the fault within 3 days after the event. At this locality, the subsidence continued probably to the end of 1980 , adding 7 to $8 \mathrm{~cm}$ of dip-slip while decaying exponentially. The horizontal and vertical postseismic parallel slip components can be combined into the projection onto a vertical plane of the postseismic displacement vector. This is shown for Worthington Road in Figure 6, indicating that the vector became more horizontally oriented as the postseismic slip progressed. Thus, the vertical afterslip came to equilibrium faster than will the horizontal slip.

Analysis of available surveys from the Harris Road alignment array indicates that, while Goulty et al. reported that $8 \mathrm{~mm}$ of displacement may have taken place coincident with the 1968 Borrego Mountain earthquake, the array was probably not sensitive to episodic displacements of less than $1 \mathrm{~cm}$. Continuing slip at a rate of roughly $2 \mathrm{~mm} / \mathrm{yr}$ was possible between April 1968 and October 1972, however (Figure 5B). 
On the Brawley fault zone, the creepmeter at Harris Road is difficult to interpret since dextral slip would reduce the distance between the piers while subsidence to the west of the fault would increase it. For this reason, its history cannot be included in Figure 5. The instrument has shown less than $3 \mathrm{~mm}$ of shortening between May 1980 and a July 1984 service trip. However, up to $1 \mathrm{~cm}$ of extension may have taken place between June and November of 1980 . This could represent a few centimeters of residual postseismic dip slip; the coseismic slip there was probably several times larger (Cohn et al., 1982).

An alignment array was established across the Brawley fault zone at Keystone Road in September 1977. During the Imperial Valley event, it measured 1 to $2 \mathrm{~cm}$ of dextral offset and 8 to $9 \mathrm{~cm}$ of subsidence to the west of the Brawley fault trace

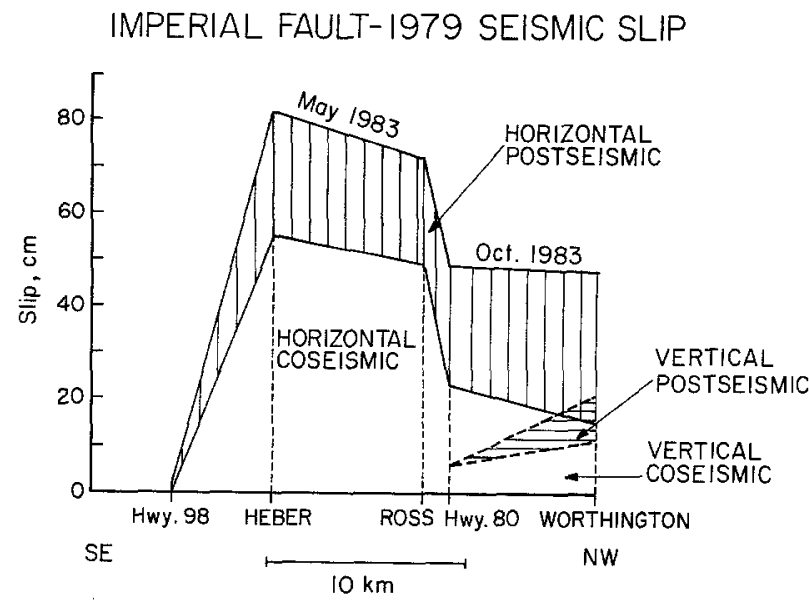

FIG. 7. Profile along the Imperial fault of seismic slip due to the 1979 Imperial Valley earthquake. The "coseismic" slips were measured within a few days of the event. Right-lateral postseismic slip is continuing at Heber, Ross, and Worthington Roads, and at Highway 80 , although it ceased 2.5 yr after the event at Highway 98 (Tuttle Ranch). Postseismic slip in the vertical direction, where it was measured at Worthington Road, also ceased after about $1 \mathrm{yr}$. Note that the amount of postseismic slip is more constant along strike than the coseismic slip, at least north of Highway 98.

within 2 days of the earthquake. No postseismic slip on either component could be reliably detected, nor has any continuing slip been resolved between September 1977 and the March 1984 survey (Figure 5A).

The distribution of postseismic deformation on the Imperial fault appears to be intimately related to its history and patterns of coseismic slip at depth. Much of the mapped surface break continues to slip horizontally as a result of the 1979 event, as shown by all of the monitored instruments and arrays north of State Highway 98 (Figure 7). It is immediately apparent that both the coseismic and postseismic slip increase rapidly to the north of this point, while the rupture of the 1940 Imperial Valley earthquake increased rapidly to the south of the same point (Sharp, 1982). Although the 1940 and 1979 displacements are comparable north of Highway 98, the 1979 rupture did not extend to the south into the area where the 1940 event had its maximum rupture of more than 5.8 meters.

Slip rates on the Imperial fault will probably remain above the preseismic $5 \mathrm{~mm} /$ yr slip rate for at least the 6 yr proposed by Cohn et al. (1982) and possibly the 9 to $10 \mathrm{yr}$ proposed by Langbein et al. (1983), while decaying exponentially. Where the fault crosses County Highway S-80, J. P. Buwalda measured $56 \mathrm{~cm}$ of displacement 
6 days after the 1940 earthquake (unpublished field notes, 1940). Brune and Allen (1967) measured $96 \mathrm{~cm}$ of displacement in 1966. Assuming that the rate of on-going slip was a constant $5.5 \mathrm{~mm} / \mathrm{yr}$ over the period from 1940 to 1979 , as measured by the alignment array there after 1967 , about $14 \mathrm{~cm}$ of the $40 \mathrm{~cm}$ accumulated from 1940 to 1966 are due to the constant slip rate. Thus the postseismic slip due to the 1940 event was at least $26 \mathrm{~cm}$. The same constant slip rate, when subtracted from the $29 \mathrm{~cm}$ of postseismic slip due to the 1979 event from 1979 to 1984 , leaves $26 \mathrm{~cm}$ also. Apparently, the postseismic slips from both events at Highway S-80 are almost exactly the same, despite the fact that the coseismic displacement of the 1940 event was about twice as large as the 1979 displacement. Alternatively, the 1940 postseismic slip may have been larger, and the on-going slip rate could have started out smaller and later increased sometime between 1940 and 1967.

Figure 7 also shows that the amount of 1979 postseismic slip is relatively constant along the strike of the fault despite the fact that the section south of Highway S-80 displayed more coseismic slip than the fault sections to the north. The maximum coseismic displacement between Heber and Ross Roads is coincident with the maximum $2 \mathrm{~m}$ of displacement found at depths of more than $5 \mathrm{~km}$ through inverse waveform modeling of strong-motion records by Hartzell and Heaton (1983). This area of maximum offset at depth appears, therefore, to affect the coseismic, but not the postseismic, slip on the surface. Farther south, however, the Tuttle Ranch creepmeter shows that afterslip ceased within $2.5 \mathrm{yr}$ of the event. Furthermore, while vertical coseismic slip was measured at both Highway 80 and Worthington Road, vertical postseismic slip was found only at Worthington Road and continued for a much shorter period than the horizontal afterslip.

The creepmeter crossing the Superstition Hills fault (Figure 1) suggests that ongoing dextral slip at a rate of $0.5 \mathrm{~mm} / \mathrm{yr}$ took place between May 1968 and August 1979 (Figure 5B). Subsequently the instrument recorded, within 3 days of the event, $11 \pm 3 \mathrm{~mm}$ of the sympathetic dextral displacement triggered by the 1979 Imperial Valley earthquake. This value agrees with those noted by Fuis (1982). Since the 1979 triggered displacement, no slip greater than about $1 \mathrm{~mm}$ has occurred up to the July 1984 reading. Apparently the small rate of continuing slip on the Superstititon Hills fault was halted by the sympathetic displacement.

An alignment array is located nearby which recorded the displacement due to the 1968 Borrego Mountain event (Allen et al., 1972). However, subsequent target location problems have made it insensitive to the small motions measured by the neighboring creepmeter, although its measurements (Figure 5A) are consistent with the creepmeter's.

The alignment array near Dixieland (Figure 1) was established across ground cracks, extending more than $1 \mathrm{~km}$, that appeared in the desert floor in 1970. They were never associated with any mapped fault and have been of debatable tectonic origin. The data from the array (Figure $5 \mathrm{C}$ ), which was surveyed 11 times between August 1970 and November 1979, show dextral slip that is almost certainly tectonic. The overall slip rate for the life of the array was $3.2 \mathrm{~mm} / \mathrm{yr}$. It is interesting that Dixieland is nearly on a line projected between the southeastern end of the Coyote Creek fault and the northwestern end of the Cerro Prieto fault (Figure 1) in Mexico. The lineations in seismicity seen in this area (Figure 8, area D) do not, however, reach the location of the Dixieland array.

Coachella Valley area. The Coachella Valley is well instrumented, with five alignment arrays and two creepmeters being maintained on the "San Andreas fault" 
southeast of the junction of the Banning and Mission Creek faults, and an alignment array on the Banning fault (Figure 1).

Results from the Coachella Valley are remarkable in that all but one alignment array demonstrate the regular occurrence of dextral slip, if not continuous creep, between most of the measurement epochs (Figure 5B). On the southern San Andreas fault, this slip is occurring even on long stretches that exhibit very low seismicity, as in area $\mathrm{E}$ of Figure 8. On the Banning fault, the array at Devers Hill has been

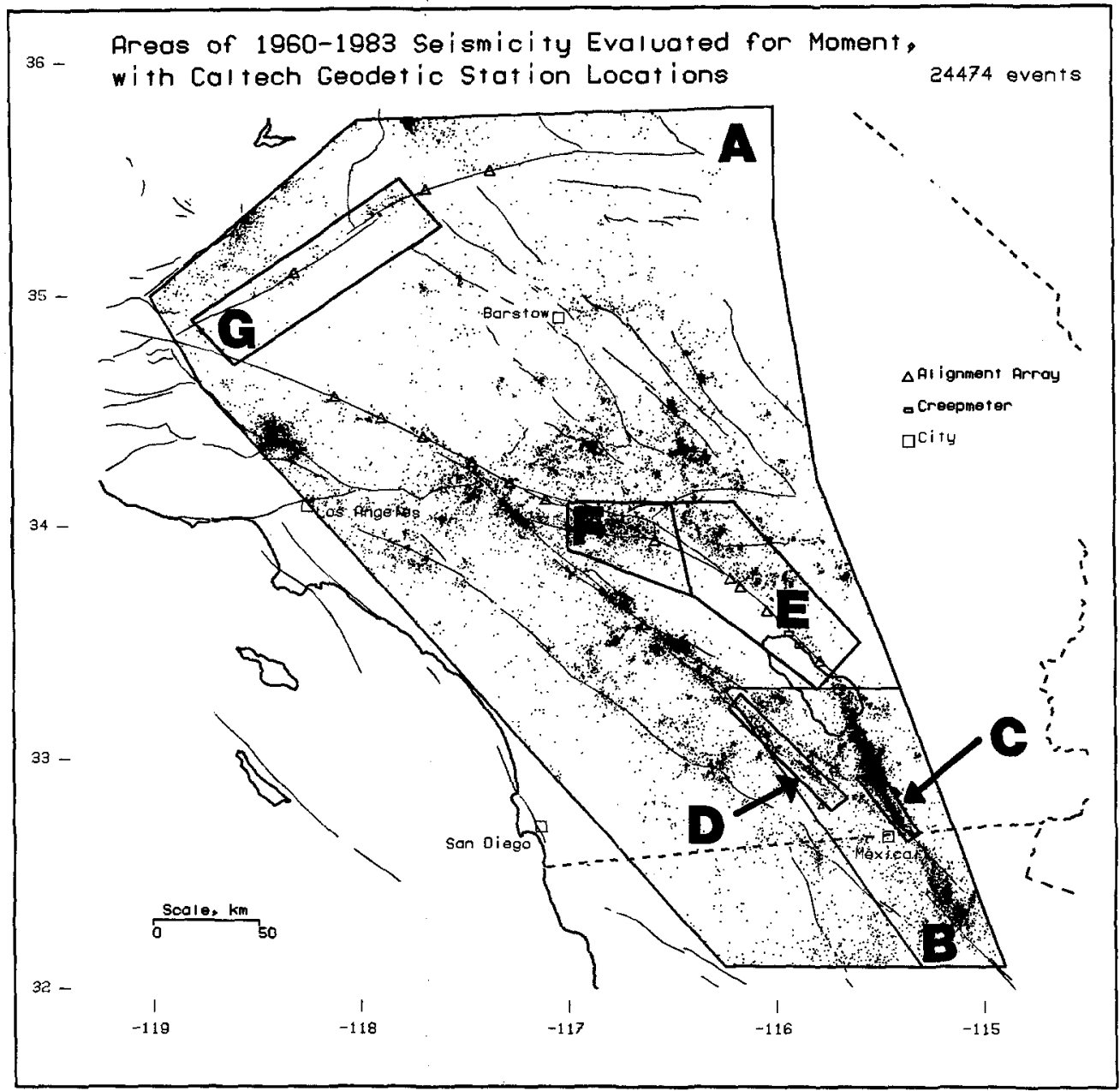

FIG. 8. Map of southern California showing the locations of all events excepting quarry blasts located within the large polygon between 1960 and 1983 by SCARLET. No magnitude or quality selection was employed. A small dot is plotted for each of the 24,474 events. Areas evaluated for seismic moment are outlined.

moving consistently at a rate of close to $2 \mathrm{~mm} / \mathrm{yr}$ at least since its second survey in 1972, validating the "suggestion of motion" found by Keller et al. (1978). This result is a little surprising since some geological lines of evidence would point to the Mission Creek fault as the most probable carrier of any movement in the area. The San Gorgonio pass area is, however, marked by strong and unusually deep seismicity extending to the west of Devers Hill (Figure 8, area F). 
On the San Andreas fault to the southeast of Devers Hill, the Indio Hills array yields a slip rate of $1.4 \mathrm{~mm} / \mathrm{yr}$ from a few targets between April 1970 and June 1977 (Figure 5B). Since then, the array has been improved to provide eight different target angles across the fault, and has shown an average slip rate of $1.8 \mathrm{~mm} / \mathrm{yr}$ from June 1977 to the November 1982 measurement. The statistical error in this rate is about $\pm 0.6 \mathrm{~mm} / \mathrm{yr}$ due to the large spread between the angles. More measurements must be taken before it can be determined if the latest February 1984 resurvey was accurate. An offset of 1 or $2 \mathrm{~mm}$ at the array during the 1979 Imperial Valley earthquake is possible, but the motion seems more likely to simply be a manifestation of the on-going slip.

At Dillon Road, the array exhibited $3 \mathrm{~mm} / \mathrm{yr}$ of slip after its installation in April 1970, until the theodolite station was apparently disturbed sometime after August 1977 (Figure 5B). Since then, the angles have diverged to the point where the slip appears to have ceased between April 1979 and February 1984. An overall rate of 2 $\pm 1 \mathrm{~mm} / \mathrm{yr}$ is obtained for Dillon Road since April 1970. One target indicates an episodic slip of perhaps 4 or $5 \mathrm{~mm}$ between April and November of 1979, coincident with the 1979 event.

At Red Canyon, the data from the alignment array clearly show dextral slip to be taking place at a rate of $3.1 \mathrm{~mm} / \mathrm{yr}$ since June 1977 (Figure 5B). The slip rate is not as clear in the preceding $9 \mathrm{yr}$ due to a lack of targets and fluctuations of almost a centimeter. However, the data suggest that significant slip did not occur during the $6 \mathrm{yr}$ following the offset of the array from slip triggered by the 1968 Borrego Mountain earthquake (Allen et al., 1972). Overall, Red Canyon shows an average rate of $1.7 \mathrm{~mm} / \mathrm{yr}$ from its installation in May 1967 to the measurement in May of 1983. As is the case for the arrays to the north, an offset triggered by the 1979 earthquake, here up to roughly $1 \mathrm{~cm}$, is possible but may be a manifestation of the continuing slip. None of these arrays was surveyed frequently enough to distinguish the two possibilities.

The array set up at North Shore has only been surveyed four times during its 15yr history. Although the last October 1984 resurvey suffered from the poor maintenance of the targets, it is clear that slip at a rate greater than a fraction of a millimeter per year has not taken place through this array (Figure $5 \mathrm{~B}$ ). A creepmeter has been maintained nearby since February 1970. It has not detected any continuous creep of more than $0.1 \mathrm{~mm} / \mathrm{yr}$, or any events larger than $1 \mathrm{~mm}$, up to the October 1984 servicing. Not more than $0.3 \mathrm{~mm}$ of displacement could have occurred this instrument due to the 1979 Imperial Valley event, nor was any ground breakage observed within several kilometers (Sieh, 1982).

At Bertram, close to the southeastern extremity of the fault, the array seems to be unstable, causing the conclusions to be quite tenuous. The history derived from averages of target pairs would be misleading and is therefore not shown. However, the records from a few angles between October 1972 and April 1979 can be interpreted as indicating 1 or $2 \mathrm{~mm} / \mathrm{yr}$ of slip. An obvious slip episode of about 1 $\mathrm{cm}$ took place between April 1979 and next survey, 3 days after the 1979 Imperial Valley earthquake. It was followed to the July 1984 measurement by a period of apparent quiescence.

The alignment arrays in the Coachella Valley have shown slip with remarkable consistency, although the variations in slip increase from northwest to southeast. Sieh (1982), in his survey of rupture on the San Andreas fault triggered by the 1979 Imperial Valley earthquake, did not observe breakage as far northwest as the Indio Hills and Dillon Road arrays; thus, there is no direct evidence of coseismic slip in 
that area. The Red Canyon array, however, sits squarely across en-echelon fractures mapped by Sieh and could be expected to show displacement. Bertram is $300 \mathrm{~m}$ from the most southeasterly breaks mapped, but may have had close to $1 \mathrm{~cm}$ of offset, a magnitude which Sieh found farther north near Red Canyon. Evidently, slip on the San Andreas fault near the Salton Sea is more affected by events around the Imperial Valley than is slip on the San Andreas fault to the north, near Indio or on the Banning fault. The Devers Hill array would have detected a coseismic slip greater than a few millimeters in October 1979; on-going slip rates at Indio Hills and Dillon Road do not appear to have been disturbed by the event.

Telemetered creep and tilt instruments were installed at Mecca Beach in April of 1981 . The creepmeter measured a continuing dextral slip rate of $0.7 \mathrm{~mm} / \mathrm{yr}$ until early April of 1984 (Figure 5B). Creep events larger than $0.1 \mathrm{~mm}$ were not detected until early April, and again in July of 1984. These events, which were coincident with tilting, will be reported on separately.

San Jacinto fault system. The San Jacinto fault system is rather sparsely instrumented due to the previous destruction of two entire alignment arrays. Arrays are presently located at Colton on the Claremont fault, at Anza on the Clark fault, and at Baileys Well on the Coyote Creek fault (Figure 1). Significant creep at the Colton array could not have occurred between October 1973 and the latest measurement in June of 1983 (Figure 5C). Nor do the data suggest any significant episodic slip events.

The Anza array is situated where the San Jacinto system splays into the Coyote Creek, Clark, and Buck Ridge faults, in a recently alluviated area where the identification of which trace may be presently active is somewhat difficult. A seismicity "gap" has developed recently surrounding the array (Sanders and Kanamori, 1984), which may make this section of the fault unrepresentative of the areas outside of the gap. Measurements from April 1977 to February 1984 show that no significant motion occurred between the two most reliable targets. Figure 5A shows the average of all target pairs. Offsets are also unlikely through the rest of the array, which spans an aperture of $270 \mathrm{~m}$, at least since the event measured by January 1973 and reported by Keller et al., (1978).

Unlike the uncertain measurements on the Claremont and Clark faults, the array at Baileys Well on the Coyote Creek fault shows well-observed continuing slip (Figure 5C). Between June 1971 and March 1984, the array has measured rightlateral slip occurring at an average rate of $5.2 \mathrm{~mm} / \mathrm{yr}$. Burford (1972) showed that postseismic slip due to the 1968 Borrego Mountain event occurred through an alignment array at the same location, at least up to February 1971. His slip data to 1971 predict that about $4 \mathrm{~cm}$ of slip would have accumulated between 1971 and 1984. The Baileys Well data show, however, that at least $5 \mathrm{~cm}$ and probably closer to $7 \mathrm{~cm}$ of slip has taken place. Therefore, it is unlikely that the on-going slip is residual postseismic deformation due to the 1968 event. This leaves the Coyote Creek fault at Baileys Well with the highest rate of nonseismic slip observed in southern California.

The long periods between measurements do not allow the resolution of any sympathetic slip triggered at Baileys Well by the 1979 Imperial Valley earthquake. A coseismic slip of up to $1 \mathrm{~cm}$ could, however, be consistent with the data. In any case, it is evident that the two periods of consistent high slip rates, from 1971 to 1973 and from 1979 to 1982, follow the 1968 Borrego Mountain and the 1979 Imperial Valley earthquakes, respectively.

To summarize, the Clark fault at Anza and the Claremont fault at Colton are not 
likely to be slipping at more than 1 or $2 \mathrm{~mm} / \mathrm{yr}$, nor have they experienced a slip event larger than about $1 \mathrm{~cm}$, since late 1973. However, these two locations may not be representative of the entire northern San Jacinto fault system. In the southern part of the system, the Coyote Creek fault has been slipping consistently, if not continuously, at an average rate of $5.2 \mathrm{~mm} / \mathrm{yr}$ since 1971 , when the on-going slip rate began to exceed the decaying rate of postseismic slip from the 1968 event.

San Andreas fault northeast of Los Angeles. This stretch of the San Andreas fault is well monitored with six alignment arrays evenly spaced at about $25-\mathrm{km}$ intervals (Figure 1). The array at Una Lake near Palmdale has held steady from its installation in February 1970 to the last survey in January 1984, with no indication of any on-going slip or episodic displacements greater than its apparent sensitivities (Figure 5A). To the southwest at Pallett Creek, the array similarly gives no evidence of any motion from February 1970 to July 1984 (Figure 5C). The array at Big Pines suffers from having too few and relatively unstable targets but shows no evidence of on-going slip, nor any episodic displacements between May 1970 and January 1981 (Figure 5C). At Cajon, only a few angles are stable enough to yield consistent measurements, so its history is not shown. However, if the active trace of the fault has been located to an accuracy of $8 \mathrm{~m}$, which is likely in view of the locally wellexposed geology, then an episodic displacement of more than $1 \mathrm{~mm}$ could be detected by the array. The data do not show any slip between February 1970 and July 1984. If the active trace were not so well located but still within the array, the sensitivity would decrease to $1 \mathrm{~cm}$. No such displacement has been manifested. The Waterman Canyon array is similar but would be insensitive to somewhat larger displacements. Significant on-going slip can be ruled out for the period from April 1970 to June 1983, although its average history has been too unstable to show here. At Santa Ana Wash on the south branch of the San Andreas fault, the array incorporates a good number of relatively stable targets. Between January 1971 and September 1983, no significant slip could have occurred (Figure 5C).

These six alignment arrays provide convincing evidence that, despite continuing slip in the Coachella Valley to the southeast, neither significant creep nor large episodic displacements have taken place on this section of the San Andreas fault since 1970 . In addition, they serve to point out the sensitivity of this small-scale triangulation technique in a variety of environments.

Garlock fault. The Garlock fault is sampled by three alignment arrays, with one at Cameron on the currently more active part of the fault west of Koehn Lake (Astiz and Allen, 1983) and two at Rand and Christmas Canyon (Randsburg Wash) on the less active eastern portion (Figure 1). The Cameron array has consistently shown left-lateral slip at an average rate of $3.7 \pm 1 \mathrm{~mm} / \mathrm{yr}$ from its establishment in January 1971 to at least April 1982 (Figure 5C). Flooding between that survey and the most recent surveys in June and August of 1983 has affected the timbers holding critical targets across the fault trace from the theodolite station such that another year of measurements will be necessary to show that slip is continuing. However, recent right-stepping, en-echelon cracks cut nearby pavements along the fault trace. In addition to the above slip rate, which is occurring within a $115-\mathrm{m}$ wide aperture that contains the geomorphically obvious trace, angles to one target suggest an additional $2 \pm 0.5 \mathrm{~mm} / \mathrm{yr}$ of sinistral slip within a $70-\mathrm{m}$ zone to the northwest of the theodolite station. Overall, it is likely that the Garlock slips at least $4 \mathrm{~mm} / \mathrm{yr}$ at Cameron.

The measurements at Cameron are supported by results from a National Geodetic Survey network crossing the southwesternmost section of the Garlock fault at Tejon 
Ranch (Snay and Cline, 1980). This location is $45 \mathrm{~km}$ southwest of Cameron and $15 \mathrm{~km}$ to the northeast of the junction between the Garlock and San Andreas faults. Triangulation and trilateration observations between 1964 and 1972 showed leftlateral slip across the south branch of the Garlock there at a rate of $1.7 \pm 0.5 \mathrm{~mm} /$ yr. This was accompanied by horizontal separation at a rate of about $3.5 \pm 2.4 \mathrm{~mm} /$ yr perpendicular to the fault trace.

The Rand alignment array has yielded some of the most consistent measurements, with a divergence between targets of less than $8 \mathrm{~mm}$ over a period of $12 \mathrm{yr}$, excepting a single target on a leaning telephone pole. Slip has not occurred there between the initial measurement in January 1971 and the last survey in February 1983 (Figure 5C). Further east at Christmas Canyon, the data are of similar quality. Measurements back to January 1971 show no significant continuing or episodic slips, up to the latest measurement in December 1983 (Figure 5C). The surface trace of the Garlock fault appears, then, to be locked for at least $60 \mathrm{~km}$ east of Koehn Lake.

\section{Discussion}

The regional picture of nonseismic slip in southern California is shown by Figure 9, which summarizes the above observations of slip not related to the 1979 Imperial Valley earthquake. Statistics pertinent to the determinations of slip rates for selected alignment arrays and creepmeter micrometer measurements are given in Table 2.

These data confirm the regional distribution of fault slip first suggested by Keller et al. in 1978. Certain facts are at once apparent: first, measured fault slips in southern California are about an order of magnitude below motions measured at greater distances away from the faults, including the measured rate of offset between the Pacific and North American plates (Savage, 1983). This differs from the slip on the San Andreas system in central California, where slip rates are comparable to the plate motion (Burford and Harsh, 1980). Second, the distribution of slipping faults in southern California agrees well with Allen's (1968) division of the San Andreas system into creeping, seismically active; and dormant, seismically quiescent sections on the basis of geological evidence. The Garlock fault can now be similarly divided, with the simple eastern trace being locked and the more complex trace southwest of Koehn Lake slipping. However, the relationship between seismic activity and slip is not always so simple. The San Jacinto system north of Anza has not shown measurable slip in the last $10 \mathrm{yr}$ despite its high level of seismic activity (Figure 8). This is unusual since one of its southern branches, the Coyote Creek fault, has shown the highest rate of continuing slip in southern California. On the other hand, the trace of the San Andreas fault through the Coachella Valley reveals substantial slip at 2 to $3 \mathrm{~mm} / \mathrm{yr}$ despite low to nil seismic activity.

Smith and Wyss (1968), Burford et al. (1973), and Wesson et al. (1973) have shown that slip rates calculated from the seismic moments of moderate earthquakes on the San Andreas fault in central California are comparable to rates observed there geodetically. In southern California, however, the fault traces are more numerous and complex, and seismicity is more diffuse (Figure 8). To try to relate the slip rates shown in Figure 9 with the regional seismicity, we can start by summing the moments of all events in southern California. Assuming the momentmagnitude relation of Thatcher and Hanks (1973),

$$
\log _{10} M_{0}=1.5 M_{L}+16
$$


where $M_{0}$ is the seismic moment of an event of local magnitude $M_{L}$, the total moment associated with the 22,527 events located within area $A$ of Figure 8 between 1970 and 1983, excepting the 1979 Imperial Valley earthquake, is $1.03 \times 10^{26}$ dyne$\mathrm{cm}$. Assuming an average slip rate of $5 \mathrm{~mm} / \mathrm{yr}$ for $14 \mathrm{yr}$ evenly distributed on a fault $10 \mathrm{~km}$ deep, the definition of moment

$$
M_{0}=\mu A u,
$$

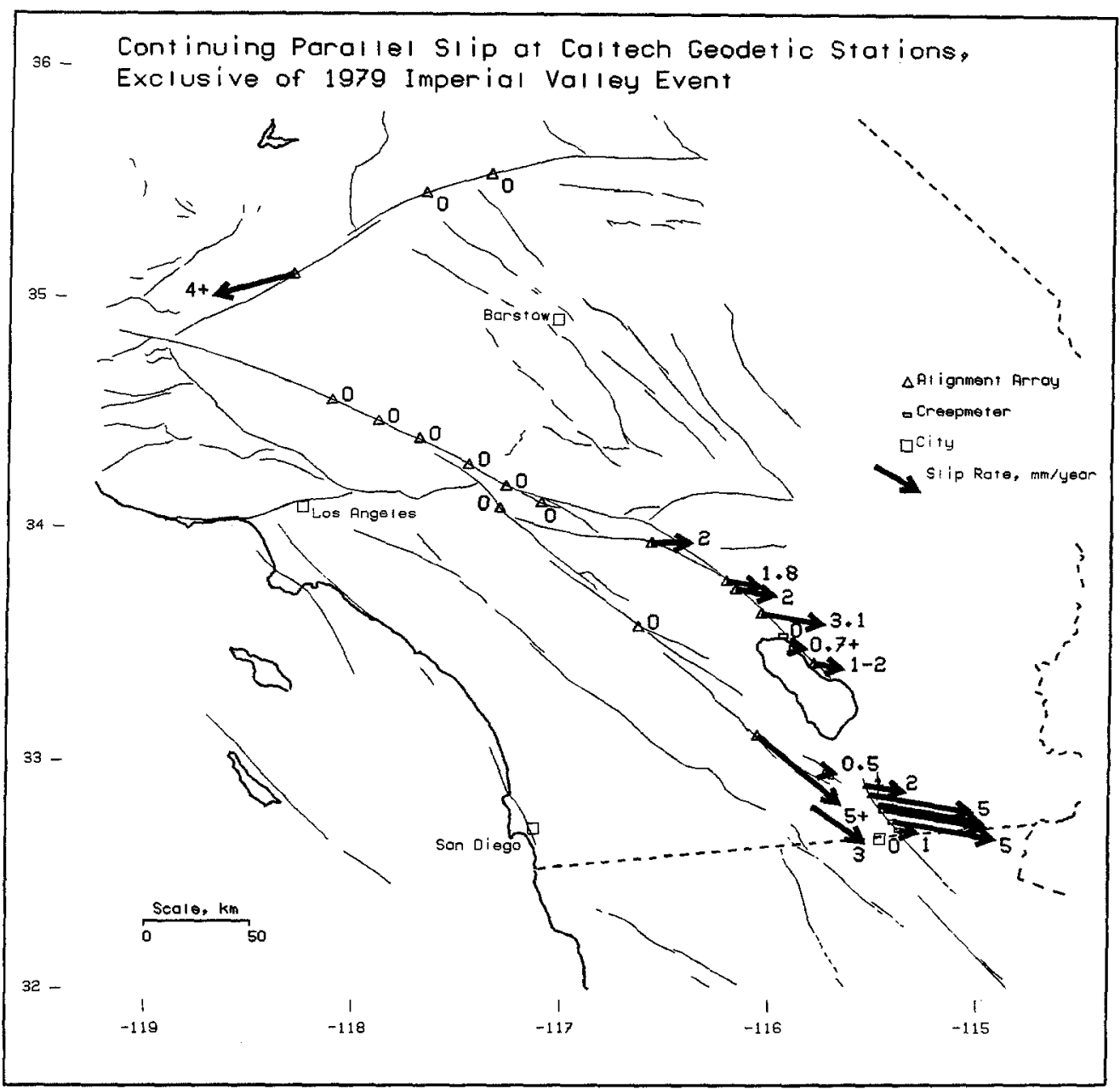

FIG. 9. Map summarizing observations in southern California of fault slip rates not associated with earthquakes showing surface rupture. All motion is assumed to be parallel to the fault traces; the arrows are oriented only for pictorial convenience and have lengths proportional to the slip rates. Note the faults on which no slip has been measured.

where $\mu$ is the rigidity of the material around the fault, which we will always assume to be equal to $3.3 \times 10^{11}$ dynes $/ \mathrm{cm}^{2}, A$ is the area of the fault plane, and $u$ is the amount of slip, shows that such a fault would be $445 \mathrm{~km}$ long. Although this calculation quite incorrectly assumes that all of the events are located on the one fault plane, the fact that the total length of the slipping faults in southern California may be as much as $400 \mathrm{~km}$ indicates that all of the on-going nonseismic slip might, by some unknown mechanism, be explained by the regional release of seismic 
moment. Even if eight more events of $M_{L} \geqq 5.5$, many of which exhibited surface rupture not reflected in Figure 9, are subtracted from the moment sum, the resulting $76 \mathrm{~km}$ fault length cannot be far from a reasonable minimum total length for slipping faults in southern California, given that continuing slip has been confirmed only at discrete points along the faults.

The catalog of earthquakes used here was compiled from events detected by the Southern California Array for Research on Local Earthquakes and Teleseisms (SCARLET). From the distribution of events detected within certain magnitude ranges, it is clear that many events of $M_{L}$ less than about 2.5 have not been located by SCARLET. It is well known, however, that such small events do not contribute substantially to the total moment. A more important source of error when consid-

TABLE 2

\begin{tabular}{|c|c|c|c|c|c|c|}
\hline Station & Fault & Period & $\begin{array}{l}\text { Slip Rate } \\
(\mathrm{mm} / \mathrm{yr})\end{array}$ & $\begin{array}{c}\text { Correlation } \\
r\end{array}$ & $\begin{array}{c}\text { Samples } \\
n\end{array}$ & $\begin{array}{l}\text { Samples } \\
\text { Omitted }\end{array}$ \\
\hline Baileys Well & Coyote Creek & $6 / 71-3 / 84$ & 5.2 & 0.87 & 153 & 35 \\
\hline Devers Hill & Banning & $10 / 72-11 / 82$ & 2.0 & 0.64 & 69 & 0 \\
\hline \multirow[t]{2}{*}{ Dillon Road } & San Andreas & $4 / 79-2 / 84$ & 0.0 & 0.01 & 45 & 9 \\
\hline & & $4 / 70-6 / 77$ & 3.0 & 0.85 & 18 & 0 \\
\hline \multirow{2}{*}{ Dixieland } & Unnamed & $1 / 71-7 / 76$ & 4.5 & 0.81 & 63 & 0 \\
\hline & & $8 / 70-11 / 79$ & 3.2 & 0.82 & 99 & 0 \\
\hline \multirow[t]{2}{*}{ Highway 80} & Imperial & $5 / 67-11 / 78$ & 5.4 & 0.62 & 279 & 0 \\
\hline & & $5 / 74-11 / 78$ & 2.5 & 0.27 & 99 & 0 \\
\hline \multirow[t]{3}{*}{ Indio Hills } & San Andreas & $6 / 77-11 / 82$ & 1.8 & 0.60 & 58 & 0 \\
\hline & & $4 / 70-2 / 84$ & 1.5 & 0.74 & 77 & 6 \\
\hline & & $4 / 70-6 / 77$ & 1.4 & 0.99 & 12 & 6 \\
\hline Mecca Beach & San Andreas & $5 / 81-2 / 84$ & 0.7 & 0.93 & 9 & 0 \\
\hline North Shore & San Andreas & $11 / 70-10 / 84$ & 0.08 & 0.58 & 49 & 0 \\
\hline Rand & Garlock & $11 / 71-2 / 83$ & 0.0 & 0.00 & 120 & 65 \\
\hline \multirow{2}{*}{ Red Canyon } & San Andreas & $6 / 77-5 / 83$ & 3.1 & 0.81 & 44 & 2 \\
\hline & & $5 / 67-5 / 83$ & 1.7 & 0.88 & 80 & 0 \\
\hline Santa Ana Wash & San Andreas & $1 / 73-12 / 81$ & 0.0 & 0.02 & 40 & 4 \\
\hline Superstition Hills & Superstition Hills & $5 / 68-8 / 79$ & 0.5 & 0.91 & 45 & 0 \\
\hline Tuttle Ranch & Imperial & $10 / 75-8 / 79$ & 1.4 & 0.97 & 19 & 0 \\
\hline
\end{tabular}

ering moment sums is variation in the rigidity of the earth materials surrounding faults in a heterogeneous crust. Still, it seems unlikely that the average rigidity of kilometer-sized volumes of southern California crust at seismogenic depths could vary enough to affect the order of magnitude comparisons considered here.

Particular fault segments must be examined in detail to define better the relationship of seismicity to fault slip. Table 3 relates seismic activity near fault traces to their measured slip. For each fault, the length of the mapped surface trace within the area of Figure 8 in question, along with the distribution of seismic activity with depth, gives the estimate of fault area in column 3 . Column 5 gives the total seismic moment derived from the local magnitudes of all events located within the area during the given period by SCARLET, from equation (2). Assuming, then, that all of these events are on the same rupture plane, the total moment can be divided by the assumed rigidity $\left(3.3 \times 10^{11}\right.$ dynes $\left./ \mathrm{cm}^{2}\right)$ and the measured slip during that period to yield, from equation (3), the rupture area in column 8 . Thus, comparing the rupture area calculated from seismic moments with the area constrained by the length of the surface trace and the distribution of events with depth yields a measure 
of whether the slip is "seismic" or "aseismic". If the rupture area demanded by the level of seismicity (column 8) is much smaller than the true area of the fault (column 3 ), then the slip can be said to be aseismic. For areas C through $\mathrm{G}$ in Table 3, it is obvious that all of the seismicity could not possibly fit into such small rupture areas.

A linear pattern of seismicity appears to accompany the southern part of the Coyote Creek fault and project toward the Superstition Hills fault (area D of Figure 8). The amount of slip calculated through equation (3) from the 1968 Borrego Mountain earthquake for a fault $12 \mathrm{~km}$ deep and the length of area D corresponds closely to the $15 \mathrm{~cm}$ of slip measured on the Coyote Creek fault immediately following the event. Since then, however, only a few millimeters of seismic slip has accumulated within area $D$, while the Baileys Well alignment array shows that the fault has slipped at least $50 \mathrm{~mm}$. The seismicity along this section of the fault since the 1968 event falls two orders of magnitude short of explaining the on-going slip, as shown by the disparity of the two rupture areas in Table 3 .

TABLE 3

Fault Rupture areas Calculated from Measured Slips and Seismicity

\begin{tabular}{clccccccc}
\hline $\begin{array}{c}\text { Area of } \\
\text { Figure 8 }\end{array}$ & Fault & $\begin{array}{c}\text { Rupture } \\
\text { Area from } \\
\text { Seismicity } \\
\text { Distribution } \\
\left(\mathrm{km}^{2}\right)\end{array}$ & Period & $\begin{array}{c}\text { Total } M_{0} \\
\left(10^{22} \text { dyne- }\right. \\
\mathbf{c m})\end{array}$ & Geodetic Station & $\begin{array}{c}\text { Measured } \\
\text { Slip }(\mathbf{c m})\end{array}$ & $\begin{array}{c}\text { Rupture } \\
\text { Area to } \\
\text { Match } \\
\text { Slip } \\
\left(\mathrm{km}^{2}\right)\end{array}$ \\
\hline B & Imperial & 760 & $1967-1983$ & 14600 & Highway 80 & 56 & 790 \\
C & Imperial & 760 & $1967-1983$ & 242 & Highway 80 & 56 & 13 \\
D & Coyote Creek & 864 & $1971-1984$ & 9.2 & Baileys Well & 6.6 & 7.0 \\
E & San Andreas & 1080 & $1967-1983$ & 11 & Red Canyon & 4.0 & 8.3 \\
F & Banning & 1100 & $1970-1983$ & 13 & Devers Hill & 1.9 & 20 \\
G & Garlock & 1440 & $1971-1982$ & 0.85 & Cameron & 2.4 & 1.1 \\
\hline
\end{tabular}

Figure 5C shows the seismic slip from area D of Figure 8, assuming that all of the events take place within an area of $5 \mathrm{~km}^{2}$. This assumption inflates the value of the seismically derived slip so that it can be directly compared to the measured slip. While the seismicity is obviously not confined to such a small area, the curves suggest that the continuing slip at Baileys Well is accompanied by a more or less continual release of seismic moment. Variations in the rate of moment release, such as the increase in 1982, do not appear to be associated with variations in the measured slip rates. This lack of correlation implies that local slip is not directly related to the minor seismicity on the fault. Perhaps the slip is driven by aseismic processes below the brittle crust, or by seismic dislocations elsewhere in the region.

The slip derived from the seismicity about the actively slipping part of the Imperial fault (area $\mathrm{C}$ of Figure 8), with the fault taken to be $20 \mathrm{~km}$ deep and 38 $\mathrm{km}$ long, fails by at least an order of magnitude to explain either the continuing slip which preceded the 1979 Imperial Valley earthquake or the postseismic slip which followed it. This is shown by the mismatch of areas in Table 3 . However, if we plot the slip derived from the seismicity of a wider region (B of Figure 8) which also includes the Cerro Prieto and Brawley seismic zones and the Coyote Creek fault, using the actual $760 \mathrm{~km}^{2}$ area of the fault, the seismic slip matches the coseismic and postseismic slip measured on the Imperial fault (Figure 5A). This is also clear from Table 3, with the two areas being nearly the same. The seismicity prior to the 1979 event is still, however, inadequate to explain the slip that was 
continuing at that time. Agreement with the postseismic slip is due mainly to two moderate-sized earthquakes, the first at the southern end of the Cerro Prieto seismic zone and the second in the north-central part of the Brawley seismic zone. The implication is that, following the 1979 earthquake, seismic dislocations on opposing ends of the fault segment showing surface slip may drive the relatively aseismic slip in between.

For the Banning and San Andreas faults in the Coachella Valley (areas E and F of Figure 8), Table 3 shows that the seismicity is also more than an order of magnitude too small to account for the slip measured there by alignment arrays. All of the events would have to take place within impossibly small areas-less than $25 \mathrm{~km}^{2}$ - to match the measured slips. Plotting the seismically derived slips by using such small areas (Figure 5B) shows, however, that the rate of seismic moment release appears to be less variable than the measured slip rates.

Table 3 shows that for the western Garlock fault (area G of Figure 8), an incredibly small rupture area of just $1 \mathrm{~km}^{2}$ must likewise be assumed to match the observed slip. Again, when the seismically derived slip is plotted assuming this small area (Figure 5C), there is no clear correlation between variations in the rate of seismic moment release and the measured rate of slip. Note that much of the seismicity clusters in the Koehn Lake area, at the edge of the segment that is likely to be slipping. This situation is similar to the Imperial fault, where the slipping fault segment is relatively aseismic while seismicity clusters near its ends.

Thus, while the total seismic moment over all of southern California appears adequate to account for the slip observed on many different faults, not one of the currently slipping segments is accompanied by enough seismicity locally to explain the slip without assuming unphysically small rupture areas. The nonseismic character of fault slip in southern California, when compared to the San Andreas system in central California, implies that the two regions have quite different mechanisms of fault motion. On the Imperial fault, which may be a transform between two spreading centers manifested in the Cerro Prieto and Brawley seismic zones (Lomnitz et al., 1970), seismic rupture at the spreading centers may drive the aseismic slip on the connecting transform. Similarly, for the Coyote Creek fault, the Coachella Valley section of the San Andreas fault, and the southwestern part of the Garlock fault, the observed slips may be driven by regional processes removed from the slipping sections of the faults. The slip may, in turn, cause some minor seismicity along the faults, but obviously this is not the major cause of the activity since the slip rates do not correlate over time with the rates of seismic moment release locally. If aseismic motion of the lower crust or of the lithosphere is driving fault slip, then the motion is apparently causing seismic activity to occur, not on the slipping faults themselves, but on structures elsewhere in the region.

\section{CONCLUSIONS}

1. Measurements of fault slip throughout southern California have been effectively made using theodolite alignment arrays and taut-wire creepmeters, generally under the assumption of rigid-block motion.

2. Continuing slip not related to earthquakes exhibiting surface rupture has been found on the southwestern Garlock, Banning, southeastern San Andreas, Coyote Creek, Superstition Hills, and Imperial faults, as well as on an unnamed fault $20 \mathrm{~km}$ west of El Centro, at rates from 0.5 to $5 \mathrm{~mm} / \mathrm{yr}$. These rates are an order of magnitude less than displacement rates measured between points at greater distances from the fault traces. 
3. Continuing slip on sections of the Superstition Hills and San Andreas faults probably ceased following their sympathetic displacement triggered by the 1979 Imperial Valley and 1968 Borrego Mountain earthquakes, respectively. On-going slip resumed after 1974 on the section of the San Andreas that probably stopped.

4. No significant slip has been found on the eastern Garlock fault, the San Andreas fault between Palmdale and San Bernardino, or on the San Jacinto fault system north of Anza. These faults are recognized to have the potential for major earthquakes.

5. Postseismic slip on the Imperial fault due to the 1979 Imperial Valley earthquake is continuing in the horizontal direction along all but the southernmost end of the surface rupture, at rates several times above the rate of preevent slip. Vertical postseismic slip near the northern end of the rupture and all of the slip at the southernmost end decayed to undetectable levels within $2.5 \mathrm{yr}$.

6. Seismicity adjacent to slipping faults is inadequate to account for their motion. They appear to be slipping aseismically in response either to seismic dislocations accumulating elsewhere in the region, or to deep aseismic motion which is expressed in seismicity on structures some distance from the faults slipping at the surface.

\section{ACKNOWLEDGMENTS}

Creep and strain studies at the Seismological Laboratory have been funded for many years by the U.S. Geological Survey, most recently under Contract 14-08-0001-21212. One of the authors (J. L.) has also been supported by an AMOCO Foundation fellowship in geophysics. The authors appreciate the generous assistance from and useful discussions with Kerry Sieh, Hiroo Kanamori, Bill Stuart, John Lower, Holly Eissler, Richard Stead, and many members of the Laboratory too numerous to mention here. Creep monitoring was initiated by Ralph Gilman, whose efforts sustained the program for many years. The continuing efforts of Kate Hutton and Carl Johnson to maintain the quality of the SCARLET catalog has made much of the analysis possible. The authors are indebted to William Prescott of the U.S. Geological Survey for his unusually thoughtful review of the manuscript and many helpful suggestions. No measurements could have been undertaken without the kind cooperation of many landowners and agencies who granted permission to install monuments and instrumentation and allowed long-term access for maintenance and surveying.

\section{REFERENCES}

Allen, C. R. (1968). The tectonic environments of seismically active and inactive areas along the San Andreas fault system, Stanford Univ. Pubs. Geol. Sci. 11, 70-82.

Allen, C. R., M. Wyss, J. N. Brune, A. Grantz, and R. E. Wallace (1972). Displacements on the Imperial, Superstition Hills, and San Andreas faults triggered by the Borrego Mountain earthquake, U.S. Geol. Surv. Profess. Paper 787, 87-104.

Astiz, L. and C. R. Allen (1983). Seismicity of the Garlock fault, California, Bull. Seism. Soc. Am. 73, $1721-1734$

Aytun, A. (1980). Creep measurements in the Ismetpasa region of the North Anatolian fault zone, in Multidisciplinary Approach to Earthquake Prediction: Proceedings of the International Symposium on Earthquake Prediction in the North Anatolian Fault Zone, Istanbul, Friedr. Vieweg \& Sohn, Braunschweig/Wiesbaden, 279-292.

Brune, J. N. and C. R. Allen (1967). A low-stress drop, low-magnitude earthquake with surface faulting: the Imperial Valley, California, earthquake of March 4, 1966, Bull. Seism. Soc. Am. 57, 501-514.

Burford, R. O. (1972). Continued slip on the Coyote Creek fault after the Borrego Mountain earthquake, U.S. Geol. Surv. Profess. Paper 787, 105-111.

Burford, R. O. and P. W. Harsh (1980). Slip on the San Andreas fault in central California from alinement array surveys, Bull. Seism. Soc. Am. 70, 1233-1261.

Burford, R. O., S. S. Allen, R. J. Lamson, and D. D. Goodreau (1973). Accelerated fault creep along the central San Andreas fault after moderate earthquakes during 1971-1973, Stanford Univ. Pubs. Geol. Sci. 13, 268-274. 
Cohn, S. N., C. R. Allen, R. Gilman, and N. R. Goulty (1982). Preearthquake and postearthquake creep in the Imperial fault and the Brawley fault zone, U.S. Geol. Surv. Profess. Paper 1254, 161-167.

Crook, C. N., R. G. Mason, and P. R. Wood (1982). Geodetic measurements of horizontal deformation on the Imperial fault, U.S. Geol. Surv. Profess. Paper 1254, 183-191.

Fuis, G. S. (1982). Displacement on the Superstition Hills fault triggered by the earthquake, U.S. Geol. Surv. Profess. Paper 1254, 145-154.

Goulty, N. R., R. O. Burford, C. R. Allen, R. Gilman, C. E. Johnson, and R. P. Keller (1978). Large creep events on the Imperial fault, California, Bull. Seism. Soc. Am. 68, 517-521.

Hartzell, S. H. and T. H. Heaton (1983). Inversion of strong ground motion and teleseismic waveform data for the fault rupture history of the 1979 Imperial Valley, California, earthquake, Bull. Seism. Soc. Am. 73, 1553-1583.

Keller, R. P., C. R. Allen, R. Gilman, N. R. Goulty, and J. A. Hileman (1978). Monitoring slip along major faults in southern California, Bull. Seism. Soc. Am. 68, 1187-1190.

Langbein, J., A. McGarr, M. J. S. Johnston, and P. W. Harsh (1983). Geodetic measurements of postseismic crustal deformation following the 1979 Imperial Valley earthquake, California, Bull. Seism. Soc. Am. 73, 1203-1224.

Lomnitz, C., F. Mooser, C. R. Allen, J. N. Brune, and W. R. Thatcher (1970). Sismicidad y tectonica de la region norte del Gulfo de California, Mexico-Resultados preliminares, Geofisica Internac. 10, $37-48$.

Sanders, C. O. and H. Kanamori (1984). A seismotectonic analysis of the Anza seismic gap, San Jacinto fault zone, Southern California, J. Geophys. Res. 89, 5873-5890.

Savage, J. C. (1983). Strain accumulation in western United States, Ann. Rev. Earth. Planet. Sci. 11, $11-43$.

Sharp, R. V. (1977). Holocene traces of the Imperial fault in south-central Imperial County, California, U.S. Geol. Surv. Open-File Rept. 77-815, 1 pl., scale 1:24,000, 5 sheets.

Sharp, R. V. (1982). Comparison of 1979 surface faulting with earlier displacements in the Imperial Valley, U.S. Geol. Surv. Profess. Paper 1254, 213-221.

Sharp, R. V., J. J. Lienkaemper, M. G. Bonilla, D. B. Burke, B. F. Fox, D. G. Herd, D. M. Miller, D. M. Morton, D. J. Ponti, M. J. Rymer, J. C. Tinsley, J. C. Yount, J. E. Kahle, E. W. Hart, and K. E. Sieh (1982). Surface faulting in the central Imperial Valley, U.S. Geol. Surv. Profess. Paper 1254, 119-143.

Sieh, K. E. (1982). Slip along the San Andreas fault associated with the earthquake, U.S. Geol. Surv. Profess. Paper 1254, 155-159.

Smith, S. W. and M. Wyss (1968). Displacement on the San Andreas fault subsequent to the 1966 Parkfield earthquake, Bull. Seism. Soc. Am. 58, 1955-1973.

Snay, R. A. and M. W. Cline (1980). Crustal movement investigations at Tejon Ranch, California, U.S. Dept. of Commerce, NOAA Technical Report NOS 87 NGS 18, 31 pp.

Thatcher, W. and T. C. Hanks (1973). Source parameters of southern California earthquakes, J. Geophys. Res. 78, 8547-8576.

Wesson, R. L., R. O. Burford, and W. L. Ellsworth (1973). Relationship between seismicity, fault creep, and crustal loading along the central San Andreas fault, Stanford Univ. Pubs. Geol. Sci. 13, 303321.

Yamashita, P. A. and R. O. Burford (1973). Catalog of preliminary results from an 18-station creepmeter network along the San Andreas fault system in central California for the time interval June 1969 to June 1973, U.S. Geol. Surv. Open-File Rept., $215 \mathrm{pp}$.

Youd, T. L. and G. F. Wieczorek (1982). Liquefaction and secondary ground failure, U.S. Geol. Surv. Profess. Paper 1254, 223-246.

\section{SEISMOLOGICAL LABORATORY}

CALIFORNIA INSTITUTE OF TECHNOLOGY

Pasadena, California 91125 (J.N.L., C.R.A., D.C.J., P.C.H.)

CONTRIBUTION No. 4104

Manuscript received 12 July 1984
Bolt, BeraneK, AND NEWMAN

CAMBRIDGE, MassachuSETTS 02139 (S.N.C.) 